\title{
Article \\ Actuating Performance Analysis of a New Smart Aggregate Using Piezoceramic Stack
}

\author{
Guangtao Lu ${ }^{1, * \mathbb{D}}$, Qi Wang ${ }^{1}$, Huijun Song ${ }^{1}$, Zhe Liu ${ }^{2}$ and Tao Wang ${ }^{2}$ \\ 1 Key Laboratory for Metallurgical Equipment and Control of Ministry of Education, Wuhan University of \\ Science and Technology, Wuhan 430081, China; wangqi201903704141@wust.edu.cn (Q.W.); \\ songhuijun@wust.edu.cn (H.S.) \\ 2 Hubei Key Laboratory of Mechanical Transmission and Manufacturing Engineering, Wuhan University of \\ Science and Technology, Wuhan 430081, China; lz1025154685@wust.edu.cn (Z.L.); \\ wangtao77@wust.edu.cn (T.W.) \\ * Correspondence: luguangtao@wust.edu.cn
}

check for updates

Citation: Lu, G.; Wang, Q.; Song, H.; Liu, Z.; Wang, T. Actuating

Performance Analysis of a New Smart Aggregate Using Piezoceramic Stack. Appl. Sci. 2021, 11, 9599. https:// doi.org/10.3390/app11209599

Academic Editor: Muhammad Junaid Munir

Received: 7 September 2021

Accepted: 12 October 2021

Published: 15 October 2021

Publisher's Note: MDPI stays neutral with regard to jurisdictional claims in published maps and institutional affiliations.

Copyright: (c) 2021 by the authors. Licensee MDPI, Basel, Switzerland. This article is an open access article distributed under the terms and conditions of the Creative Commons Attribution (CC BY) license (https:// creativecommons.org/licenses/by/ $4.0 /)$.
Featured Application: Structural health monitoring of concrete structures.

Abstract: A new type of smart aggregate using piezoceramic stack (SAPS) was developed for improved output, as compared with a conventional smart aggregate with a single piezoceramic patch. Due to the better output, the proposed smart aggregate is preferred where the attenuating effect is strong. In this research, lead zirconate titanate (PZT) material in the form of discs was used due to its strong piezoelectric performance. For analysis, the proposed SAPS was simplified to a onedimensional axial model to investigate its electromechanical and displacement output characteristics, and an experimental setup was designed to verify the simplified model. Moreover, the influence of the structural parameters, including the number of the PZT discs, the dimensions of the PZT disc, protective shell, and copper lids, and the elastic modulus of the epoxy on the electromechanical and displacement output performance of SAPSs, were numerically studied by using the one-dimensional axial model. The numerical analysis results indicate that the structural dimension of the PZT discs has a greater effect on the electromechanical performance of SAPSs than that of the protective shell and copper lids. Moreover, the results show that the number of the PZT discs and the outer diameter of the protective shell have a much greater influence on the displacement output of SAPSs than other parameters. The analysis results of SAPSs with different elastic moduli of the epoxy demonstrate that the SAPSs' first resonance frequency, first electromechanical coupling factor, and displacement output change less than $1.79 \%$ when the epoxy's elastic modulus changes from 1.28 GPa to $5.12 \mathrm{GPa}$, which indicates that the elastic modulus of the epoxy has a limited influence on the property of SAPSs, and it will be helpful for their fabrication. This study provides an approach to increasing the output of SAPS and also develops a method to design the structure of SAPSs.

Keywords: smart aggregate; smart aggregate using piezoceramic stack (SAPS); lead zirconate titanate (PZT) disc; transducers

\section{Introduction}

Worldwide, the conditions for civil infrastructures are deteriorating [1] due to many adverse factors, such as aging [2], corrosion [3-5], fatigue [6,7], etc. Structural health monitoring (SHM) [8,9] is playing an increasingly important role in the safety and reliability of infrastructures by providing real-time early warnings of structural abnormities $[10,11]$ based on the integrated sensors [12,13] and advanced algorithms [14]. As one of the many transducers employed in the field of SHM, piezoelectric transducers possess the advantages of low cost, quick response [15,16], wide bandwidth [17], sensing and actuation [18,19], energy harvesting $[20,21]$, enabling many applications from passive applications, such as vibration sensing [22] and acoustic emission detection [23], to active applications, such 
as SHM based on active sensing [24,25] and electromechanical impedance [26-28]. Since the introduction of the piezoceramic-based smart aggregate (SA) [29-31] that provides an effective way to protect the fragile piezoceramic patch, piezoceramic transducers have been employed extensively in concrete structures. Some of them play the role of an actuator to transmit ultrasounds in concrete, and others work as sensors to detect the signals with the change of material or structure properties [32-35]. After further processing the measured waves, various types of damages are detected or located, and the health state or lifespan of the structure is also estimated. Recently, cracks [36-38], blast or impact load [39-41], leakage [42], debonding or bond slip [43,44], corrosion [45], and concrete strength or water percentage [46-48] in different types of concrete structures, such as pipes [42], beams [49,50] and columns [51], are monitored by using SAs.

In a typical structure of SAs, there are mainly piezoelectric wafers, a water-proof and insulation layer, a protective housing, and a shielded cable. Since the first SA design $[24,25,29,30]$, the structures of SAs have been improved to meet the new requirements of SHM in concrete structures. The earliest SA was protected by a concrete shell, and it was used to transmit an elastic stress wave in a fixed direction $[29,30]$. To prevent structure destruction under impact load and increase the service time of SAs, a marble shell was used to replace the concrete one $[52,53]$ in the next generation of SAs, and a copper shield was also added to increase the signal to noise ratio. A new tubular SA was proposed by Gao et al. [54-56], and a piezoelectric tubular cylinder was used in this SA to excite omni-directional stress waves in a two-dimensional space. Nearly at the same time, a spherical SA, where the traditional piezoelectric patch was replaced by a piezoelectric spherical shell, was proposed by Kong et al. $[13,57]$ to excite ultrasonic waves in all the directions in a three-dimensional structure. The main advantage of the tubular and spherical SAs is to generate uniform stress waves in two-dimensional (2D) and three-dimensional (3D) structures, respectively. To decrease the labor cost due to cable management, a wireless SA sensor was proposed to replace the traditional wired SA by using the Zigbee protocol [58]. Moreover, the electromechanical performance of SAs with a marble shell was investigated theoretically and experimentally by Wang et al. [59] by using the theory of piezoelasticity [60-62].

The recent focus of SAs mainly involves their structural improvement and practical applications. However, how to increase the output of SAs is usually ignored. In recent decades, the piezoelectric stack actuator is employed extensively for force or displacement control in precision engineering including optical instruments, robotics, and MEMS. In a stack actuator, several piezoelectric pieces are piled up electrically and mechanically, and therefore, its output of force and displacement is significantly increased. However, the piezoelectric stack has never been applied in SAs. In addition, the energy of the stress waves is easily dissipated, and the waves usually travel a relatively short distance in the concrete structure [63]. Therefore, SAs with large output will be beneficial in damage detection in concrete structures, especially in large-scale structures. In our study, a novel type of smart aggregate using piezoceramic stack (SAPS) is proposed to improve the traditional SA's performance. Due to its strong piezoelectric effect, lead zirconate titanate (PZT) material in the form of discs was adopted, and the discs were connected in series to form a stack, which was used to replace the single traditional piezoelectric patch in the traditional SA. SAPS can significantly increase the output of a smart aggregate. To facilitate the theoretical and numerical studies, the proposed SAPS was simplified to a one-dimensional axial model to theoretically investigate the electromechanical and displacement output characteristics of SAPSs, and the influence of the structural parameters and the elastic modulus of the epoxy on the output performance were analyzed. Experiments were also conducted to validate the analytical and numerical results.

The rest of the paper is organized as follows: Section 2 proposes a simplified onedimensional axial model by using the theory of piezoelasticity and compares the performance of SAPS and the traditional SA. Section 3 investigates the electromechanical and 
output performance of SAPS by using the simplified model and presents the experimental validation. Lastly, Section 4 concludes the paper.

\section{Basic Theory of SAPS}

\subsection{The Structure and Simplified Model of SAPS}

As shown in Figure 1, SAPS mainly consists of a protective shell, a PZT stack, two copper lids (lid I and lid II), epoxy, and a shielding cable. The PZT stack is comprised of PZT discs connected in series, and the epoxy is filled in the gap between the cylinder and stack. When the PZT stack is fabricated, the adjacent two PZT discs are bonded together by conductive adhesive under a constant pressure force of $150 \mathrm{~N}$ for at least $12 \mathrm{~h}$. After the PZT stack is fabricated, the shielding cable is soldered to the lateral side of the PZT stack. Lastly, all the parts are assembled by epoxy resin under a constant force of $150 \mathrm{~N}$ for at least $24 \mathrm{~h}$. The clearance between the PZT stack and the protective shell is filled with epoxy resin before the two lids are fixed.

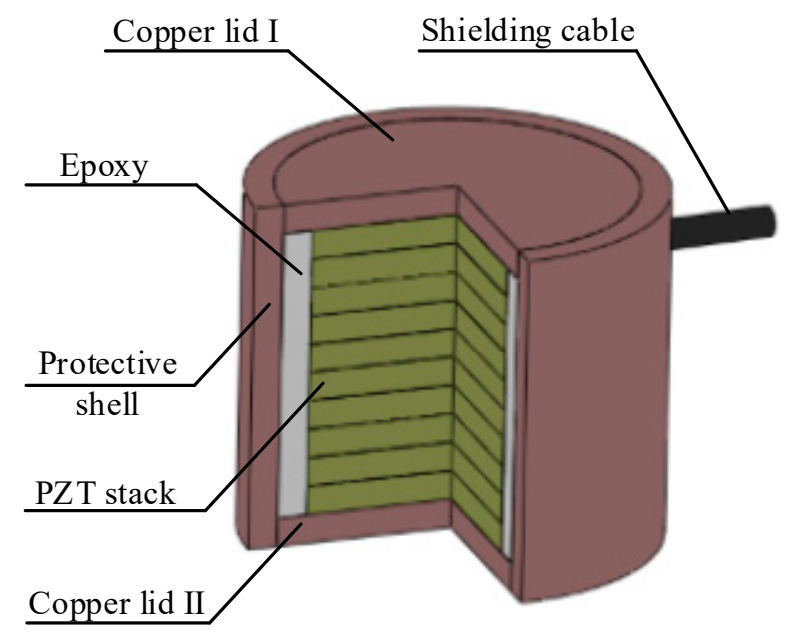

Figure 1. The Structure of SAPS.

With the consideration that SAPS is usually used to excite an elastic stress wave in the axial direction, to study its performance, SAPS is simplified to a one-dimensional axial model, as shown in Figure 2. In this simplified model, $n$ PZT discs are stacked in series. The polarization direction is along the $z$-axis, and its positive direction is along the positive $z$-axis. As shown in Figure 2, the thickness of the two lids is the same, as represented by $h_{l}$; the inner and outer diameters of the protective shell are din and $d_{0}$, respectively; the diameter and thickness of the PZT disc are $d_{p}$ and $h_{p}$, respectively. The height of the cylinder varies with the number of the connected PZT discs. The input voltage of SAPS is $U(t)$. It should be noted that the thickness and properties of the PZT discs in SAPS are the same.

\subsection{Basic Equations}

The constitutive equations of the $i$ th PZT disc and elastic materials including the epoxy and protective shell are given by [53]

$$
\begin{aligned}
& \left\{\begin{array}{l}
\sigma_{p z t i}=C_{33 p z t} \varepsilon_{p z t i}-e_{33} E_{i} \\
D_{i}=e_{33} \varepsilon_{p z t}+\kappa_{33}^{\varepsilon} E_{i} \\
E_{i}=-\frac{\partial \phi_{i}}{\partial z} \\
\frac{\partial D_{i}}{\partial z}=0
\end{array}\right. \\
& \qquad\left\{\begin{array}{l}
\sigma_{s i}=C_{33 s} \varepsilon_{s i} \\
\sigma_{e i}=C_{33 \varepsilon_{e i}}
\end{array} \quad i=1,2, \cdots, n\right. \text { (Piezoelectric materials), }
\end{aligned}
$$


where $\sigma_{p z t i}$ and $\varepsilon_{p z t i}$ are the stress and strain of the $i$ th PZT disc in the $z$-axis direction, respectively; $\sigma_{e i}$ and $\varepsilon_{e i}$ are the stress and strain of the epoxy in the clearance between the protective shell and the PZT disc in the $z$-axis direction, respectively; $\sigma_{s i}$ and $\varepsilon_{s i}$ are the stress and strain of the protective shell in the $z$-axis direction, respectively; $\phi_{i}, E_{i}$ and $D_{i}$ are the electric potential, electric field, and electric displacement of the PZT disc, respectively; $C_{33 e}$, $C_{33 s}$, and $C_{33 p z t}$ are the elastic moduli of the epoxy, the protective shell, and the PZT disc, respectively; $e_{33}=C_{33 p z t} d_{33}, \kappa_{33}^{\varepsilon}=\kappa_{33}^{\sigma}-C_{33 p z t} d_{33}^{2}$, where $d_{33}$ and $\kappa_{33}^{\sigma}$ are the piezoelectric coefficient and permittivity coefficient, respectively.

Moreover, the kinematic equation at the $i$ th composite layer of the protective shell, the $i$ th PZT disc, and the epoxy, as shown in Figure 3, can be expressed as

$$
\frac{\partial F_{c i}}{\partial z}=\left(\rho_{p z t} S_{p z t}+\rho_{e} S_{e}+\rho_{s} S_{s}\right) \frac{\partial^{2} u_{c i}}{\partial t^{2}} i=1,2, \cdots, n,
$$

where $S_{p z t}=\pi d_{p z t}^{2} / 4, S_{s}=\pi\left(d_{o}^{2}-d_{i n}^{2}\right) / 4, S_{e}=\pi\left(d_{p z t}^{2}-d_{i n}^{2}\right) / 4, F_{c i}$ and $u_{c i}$ is, respectively, the normal force and the displacement at the $i$ th composite layer in the $z$-axis direction; $\rho_{s}, \rho_{p z t}$, and $\rho_{e}$ are the densities of the protective shell, PZT disc, and epoxy, respectively; $d_{p z t}, d_{0}$, and $d_{i n}$ are the diameter of the PZT disc and the outer and inner diameters of the protective shell, respectively; $t$ is the time.

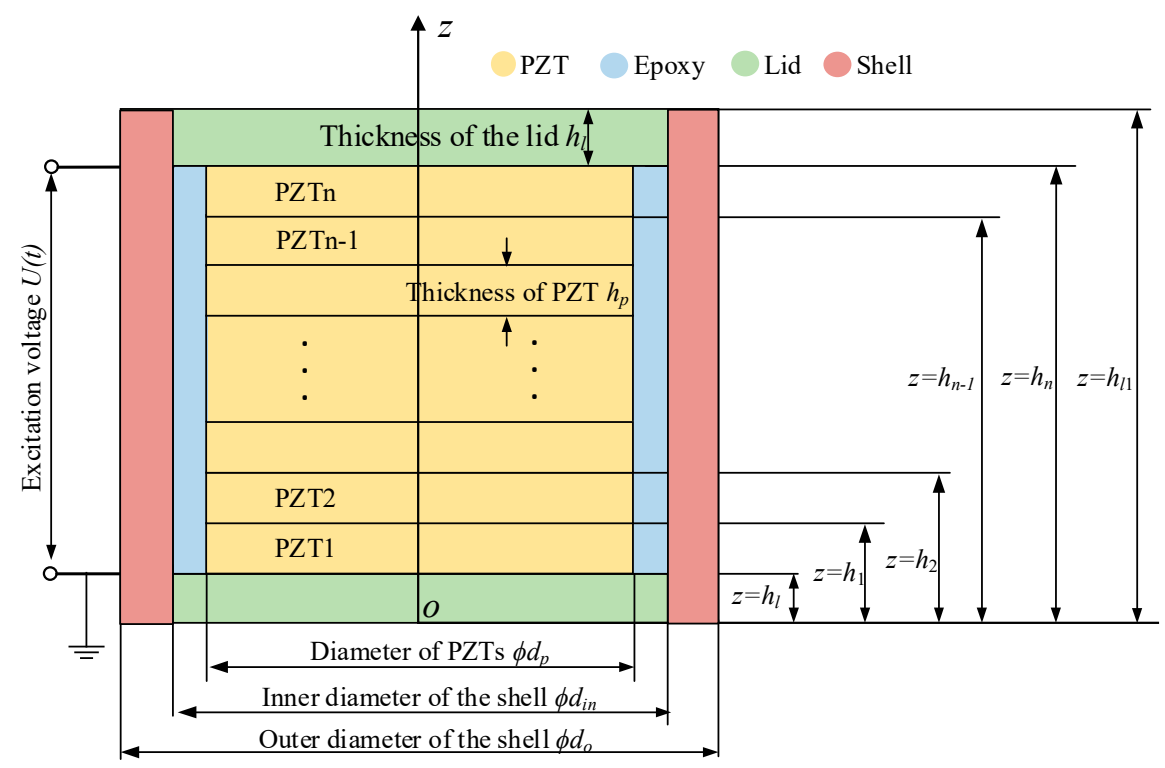

Figure 2. The simplified one-dimensional axial model of SAPS.

Normal force $F_{c i}$

Displacement $U_{c i}$

Electric potential $\phi_{i}$

PZT Epoxy Shell

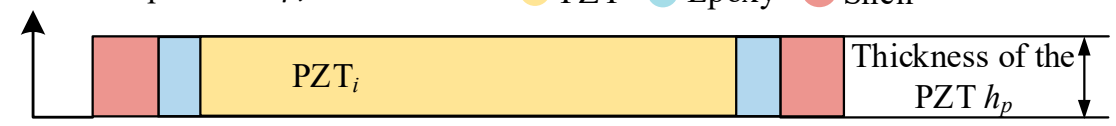

Figure 3. The composite layer of the protective shell, the $i$ th PZT disc, and epoxy.

Additionally, we have the following relationships:

$$
\left\{\begin{array}{l}
F_{c i}=\sigma_{p z t i} S_{p z t}+\sigma_{e i} S_{e}+\sigma_{\mathrm{si}} S_{s} \\
\varepsilon_{p z t i}=\varepsilon_{s i}=\varepsilon_{e i}=\frac{\partial u_{c i}}{\partial z}
\end{array} \quad i=1,2, \cdots, n,\right.
$$


Combining Equations (1)-(4) gives the following expressions:

$$
\left\{\begin{array}{c}
\chi_{0} \frac{\partial^{2} u_{c i}}{\partial z^{2}}=\chi_{1} \frac{\partial^{2} u_{c i}}{\partial t^{2}} \\
\frac{\partial E_{i}}{\partial z}=-\chi_{2} \frac{\partial^{2} u_{c i}}{\partial z^{2}}
\end{array} \quad i=1,2, \cdots, n,\right.
$$

where the constants are $\chi_{0}=S_{p z t}\left(C_{33 p z t}+\chi_{3}\right)+S_{s} C_{33 s}+S_{e} C_{33 e}, \chi_{1}=S_{p z t} \rho_{p z t}+S_{s} \rho_{s}+$ $S_{e} \rho_{e}, \chi_{2}=e_{33} / \kappa_{33}^{\varepsilon}$ and $\chi_{3}=e_{33}^{2} / \kappa_{33}^{\varepsilon}$.

Suppose that a harmonic voltage is loaded to the SAPS actuator and is expressed by

$$
U(t)=U_{0} e^{j 2 \pi f t}
$$

where $U_{0}$ and $f$ are the amplitude and frequency of the inputted harmonic voltage, respectively; and $j$ is the unit imaginary number.

Therefore, the displacement $u_{c i}$, electric potential $\phi_{i}$, and normal force $F_{c i}$ for the harmonic and steady vibration can be obtained as

$$
\left\{\begin{array}{l}
u_{c i}=u_{c i}(z) e^{j 2 \pi f t} \\
\phi_{i}=\phi_{i}(z) e^{j 2 \pi f t} \\
F_{c i}=F_{c i}(z) e^{j 2 \pi f t}
\end{array} \quad i=1,2, \cdots, n\right.
$$

where $F_{c i}(z), u_{c i}(z)$, and $\phi_{i}(z)$ are the amplitude of the normal force, displacement, and electric potential at the $i$ th composite layer, respectively.

Combing Equation (1) and Equations (5)-(7) yields

$$
\left\{\begin{array}{l}
u_{c i}(z)=A_{c i} \sin \left(k_{c} z\right)+B_{c i} \cos \left(k_{c} z\right) \\
\phi_{i}(z)=\chi_{2}\left[A_{c i} \sin \left(k_{c} z\right)+B_{c i} \cos \left(k_{c} z\right)+C_{c i} z+D_{c i}\right] \\
F_{c i}(z)=\chi_{0} k_{c}\left[A_{c i} \cos \left(k_{c} z\right)-B_{c i} \sin \left(k_{c} z\right)\right]+\chi_{3} S_{\mathrm{pzt}} C_{c i}
\end{array} \quad i=1,2, \cdots, n\right.
$$

where $k_{c}^{2}=4 \pi^{2} \chi_{1} f^{2} / \chi_{0} ;$ and $A_{\mathrm{c} i}, B_{\mathrm{c} i}, C_{\mathrm{c} i}$, and $D_{\mathrm{c} i}$ are constants related to the boundary conditions of SAPS.

Additionally, the similar expressions for displacement $u_{l i}(z)$ and normal force $F_{l i}(z)$ of the composite of the copper lid (lid I or lid II) and protective shell (as shown in Figure 4) are

$$
\left\{\begin{array}{l}
u_{l i}(z)=A_{l i} \sin \left(k_{l} z\right)+B_{l i} \cos \left(k_{l} z\right) \\
F_{l i}(z)=\chi_{4} k_{l}\left[A_{l i} \cos \left(k_{l} z\right)-B_{l i} \sin \left(k_{l} z\right)\right]
\end{array} \quad i=1,2,\right.
$$

where $\chi_{4}=C_{33 l} S_{l}+C_{33 s} S_{s}, \chi_{5}=\rho_{l} S_{l}+\rho_{s} S_{s}, k_{l}^{2}=4 \pi^{2} f^{2} \chi_{5} / \chi_{4}, S_{l}=\pi d_{\text {in }}^{2} / 4, C_{33 e}$ and $\rho_{e}$ are the elastic moduli and density of the copper lids, and $A_{l i}$ and $B_{l i}$ are the constants related to the boundary conditions.

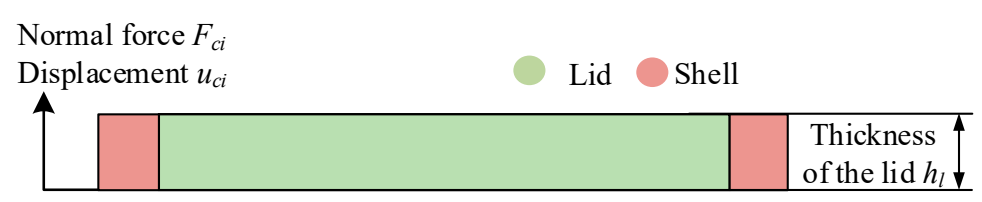

Figure 4. The composite layer of the protective shell and copper lid.

Equations (8) and (9) indicate that there is a total of $4+4 n$ constants, and we obtain $4+4 n$ equations to solve these constants by using mechanical and electric boundary conditions of SAPS in the next two sections. 


\subsection{Mechanical Boundary Conditions}

The normal force and displacement of each part at $z=0, z=h_{1}, z=h_{i-1}, z=h_{n}$ and $z=h_{l 1}$ have equations as

$$
\begin{aligned}
& \left\{\begin{array}{l}
\left.F_{l 1}(z)\right|_{z=0}=0,\left.F_{l 2}(z)\right|_{z=h_{l 1}}=0 \\
\left.F_{c 1}(z)\right|_{z=h_{l}=\left.F_{l 1}(z)\right|_{z=h_{l}}} \\
\left.F_{c n}(z)\right|_{z=h_{n}}=\left.F_{l 2}(z)\right|_{z=h_{n}} \\
\left.F_{c i-1}(z)\right|_{z=h_{i-1}}=\left.F_{c i}(z)\right|_{z=h_{i-1}}
\end{array} \quad i=2,3, \cdots, n,\right. \\
& \left\{\begin{array}{l}
\left.u_{c 1}(z)\right|_{z=h_{1}}=\left.u_{11}(z)\right|_{z=h_{1}} \\
\left.u_{c n}(z)\right|_{z=h_{n}}=\left.u_{12}(z)\right|_{z=h_{n}} \\
\left.u_{c i-1}(z)\right|_{z=h_{i-1}}=\left.u_{c i}(z)\right|_{z=h_{i-1}}
\end{array} \quad i=2,3, \cdots, n,\right.
\end{aligned}
$$

\subsection{Electric Boundary Conditions}

Since the PZT discs are connected electrically in series, the current in each PZT is the same and it is given by

$$
\begin{gathered}
I_{p z t i}(t)=\frac{\mathrm{d} Q_{i}(t)}{\mathrm{d} t}=\frac{\mathrm{d} \int_{p z t} D_{i}(t) \mathrm{d} s}{\mathrm{~d} t}=j 2 \pi f S_{p z t} e_{33} C_{c i} U_{0} e^{j 2 \pi f t}=I_{p z t i}(f) e^{j 2 \pi f t} \\
I_{p z t 1}(t)=I_{p z t 2}(t)=\cdots=I_{p z t i}(t)
\end{gathered}
$$

where $I_{p z t i}(f)=j 2 \pi f S_{p z t} e_{33} C_{c i} U_{0}$.

Therefore, yields

$$
C_{\mathrm{c} 1}=C_{\mathrm{c} 2}=\cdots=C_{\mathrm{c} i}=\text { cons }
$$

Additionally, the electric potential of PZT disc at $z=h_{11}, z=h_{n}$ and $z=h_{i-1}$ has expressions as

$$
\left\{\begin{array}{l}
\left.\phi_{1}(z)\right|_{z=h_{l 1}}=0 \\
\left.\phi_{n}(z)\right|_{z=h_{n}=U_{0}} \\
\left.\phi_{i-1}(z)\right|_{z=h_{i-1}}=\left.\phi_{i}(z)\right|_{z=h_{i-1}} \quad i=2,3, \cdots, n-1
\end{array}\right.
$$

\subsection{Analytical Solutions}

Combining the basic Equations (8) and (9) and the boundary condition Equations (10), (11), (14) and (15), $4+4 n$ equations are derived to solve the $4+4 n$ constants for a given frequency $f$ by numerical computation.

After the constants are obtained, the electrical impedance of SAPS is expressed as

$$
Z(f)=\frac{U(t)}{I_{p z t i}(t)}=\frac{U_{0}}{I_{p z t i}(f)}
$$

Equation (16) indicates that the electrical impedance of SAPS is the function of the frequency $f$, and the resonance frequency $f_{\mathrm{r}}$ and anti-resonance frequency $f_{\mathrm{a}}$ of SAPS are frequency points, where the impedance reaches the minimum and peak values, respectively.

Moreover, the electromechanical coupling factor of SAPS is given by [64]

$$
k^{2}=\frac{f_{\mathrm{a}}^{2}-f_{\mathrm{r}}^{2}}{f_{\mathrm{a}}^{2}}
$$

\section{Comparison and Discussion}

\subsection{Parameters of SAPSS}

In this section, the electromechanical and displacement output performances of SAPSs are investigated and compared. The material type of the protective shell and the 
two copper lids are copper, the type of the PZT disc is PZT-5, and the epoxy type is Pattex Power Epoxy (type PKM12C-1). Tables 1 and 2 are the material and structural parameters of SAPS, respectively.

Table 1. Material parameters.

\begin{tabular}{cccc}
\hline Name & PZT-5 & Copper & Epoxy \\
\hline Density $\rho\left(\mathrm{kg} / \mathrm{m}^{3}\right)$ & 7450 & 8800 & 1650 \\
Elastic modulus $C_{33}(\mathrm{GPa})$ & 90 & 90 & 3.2 \\
Piezoelectric coefficient $d_{33}(\mathrm{pC} / \mathrm{N})$ & 420 & $/$ & $/$ \\
Permittivity coefficient $\kappa_{33}^{\sigma}(\mathrm{F} / \mathrm{m})$ & $1.947 \times 10^{-8}$ & $/$ & $/$ \\
\hline
\end{tabular}

Table 2. Structural parameters.

\begin{tabular}{cc}
\hline Name & Parameters $(\mathbf{m m})$ \\
\hline Diameter of PZT $d_{p}$ & 10 \\
Thickness of PZT $h_{p}$ & 1 \\
Thickness of lid I and II $h_{l}$ & 1 \\
Outer diameter of protective shell $d_{o}$ & 14 \\
Inner diameter of protective shell $d_{i n}$ & 12 \\
\hline
\end{tabular}

\subsection{Influence of the Parameters of PZT Discs}

Figure 5 shows the influence of the number of the PZT discs on the first resonance frequency and the first electromechanical coupling factor, and Figure 6 plots the influence of the number of the PZT discs on the displacement of SAPS at $z=h_{l 1}$ with the frequency $f=20 \mathrm{kHz}$.

Figure 5 reveals that the first resonance frequency decreases from $303.25 \mathrm{kHz}$ to $57.96 \mathrm{kHz}$ when the number of PZT discs changes from 2 to 20. Figure 5 also shows that the first electromechanical coupling factor increases and reaches the peak value of 0.421 when the number is 6 , and then it decreases. The changing trend of the coupling factor demonstrates that there exists an optimal number that makes the coupling factor reaches the maximum value. Figure 6 indicates that the displacement at $z=h_{l 1}$ increases $11.95 \%$ as the number of the PZT discs increases from 2 to 20 , which demonstrates that the displacement output of SAPSs can be increased by increasing the number of the connected PZT discs.

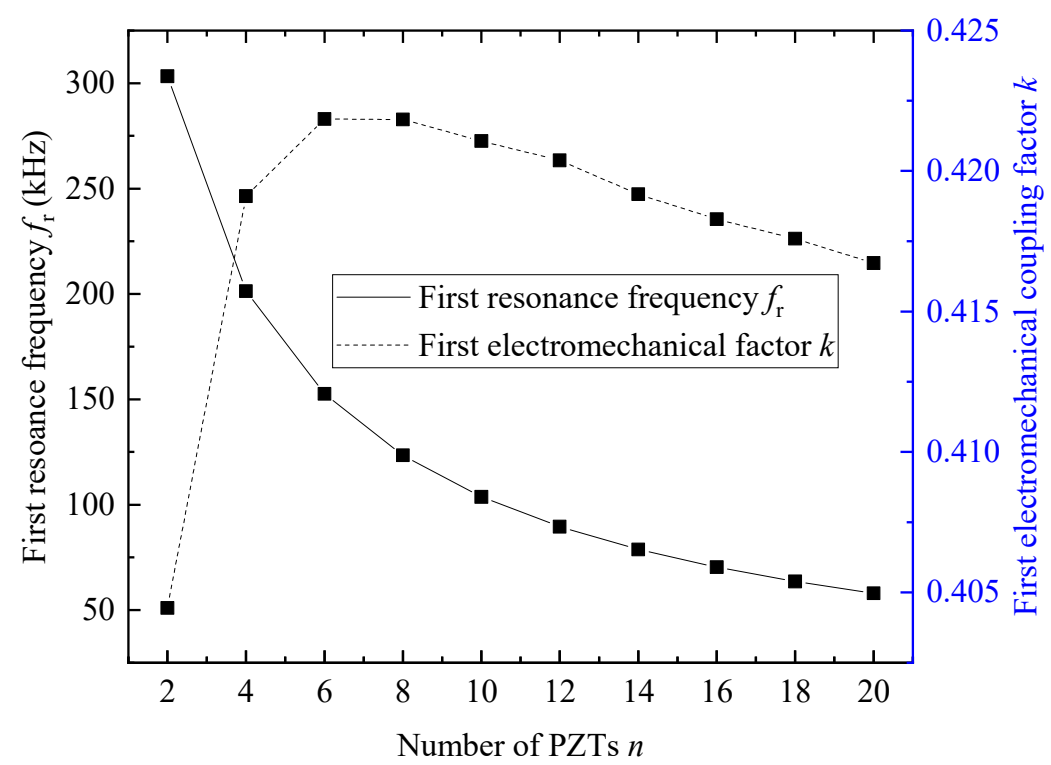

Figure 5. The influence of the number of the PZT discs on the first resonance frequency and electromechanical factor of SAPSs. 


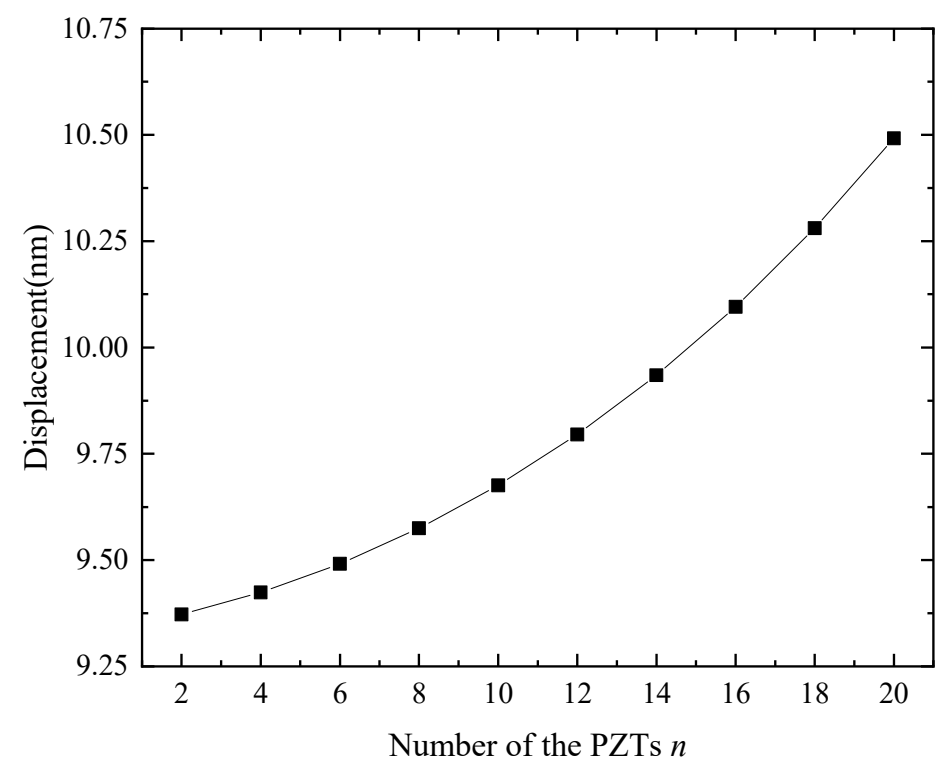

Figure 6. The influence of the connected number of the PZT discs on the displacement at $z=h_{l 1}$ with the frequency $f=20 \mathrm{kHz}$.

Figure 7 describes the influence of the thickness of the PZT disc on the first resonance frequency and the first electromechanical coupling factor, and Figure 8 illustrates the relationship between the displacement at $z=h_{l 1}$ and the thickness of the PZT $h_{p}$ at the frequency $f=20 \mathrm{kHz}$. It is clear from Figure 7 that the first resonance frequency decreases from $576.31 \mathrm{kHz}$ to $70.34 \mathrm{kHz}$ as the thickness of the PZT increases from $0.2 \mathrm{~mm}$ to $2 \mathrm{~mm}$. Figure 7 also shows that when the thickness is $0.6 \mathrm{~mm}$, the first electromechanical coupling factor saturates regardless of the number of the PZT disc. Figure 8 indicates that the displacement of SAPS with the number of PZT discs 2, 4, 6, and 8 at $z=h_{l 1}$ increases $0.879 \%, 2.42 \%, 4.70 \%$, and $7.82 \%$ as the thickness increases from $0.2 \mathrm{~mm}$ to $2 \mathrm{~mm}$.

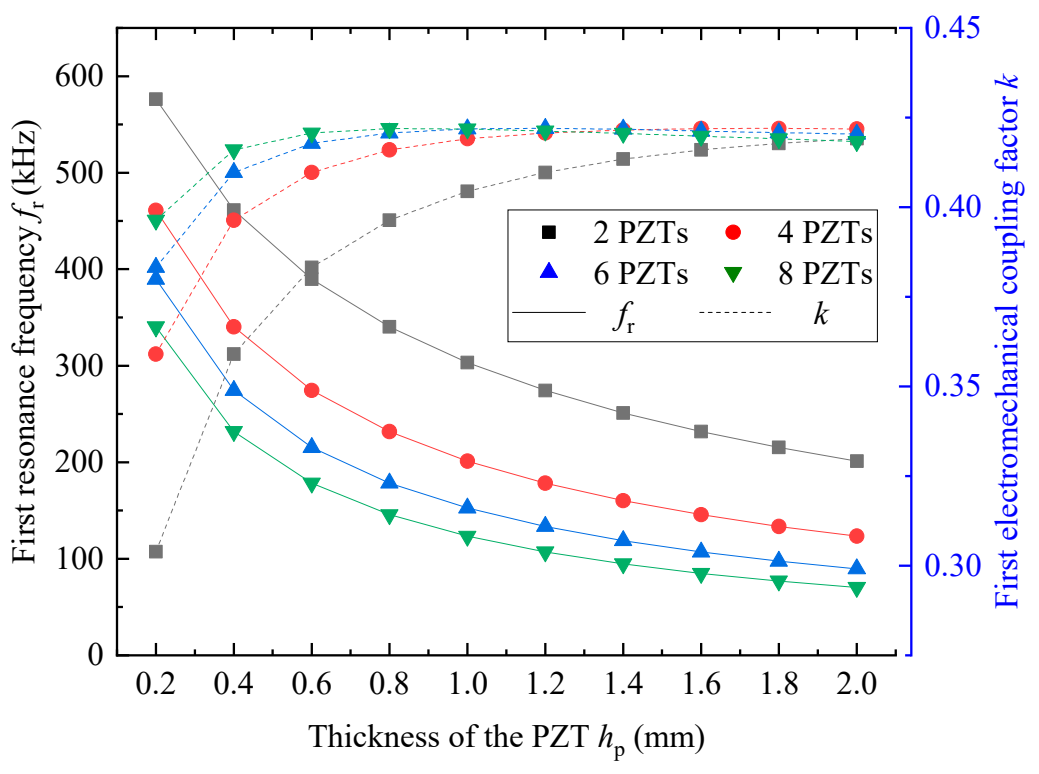

Figure 7. The influence of the thickness of the PZT $h_{p}$ on the first resonance frequency and electromechanical factor. 


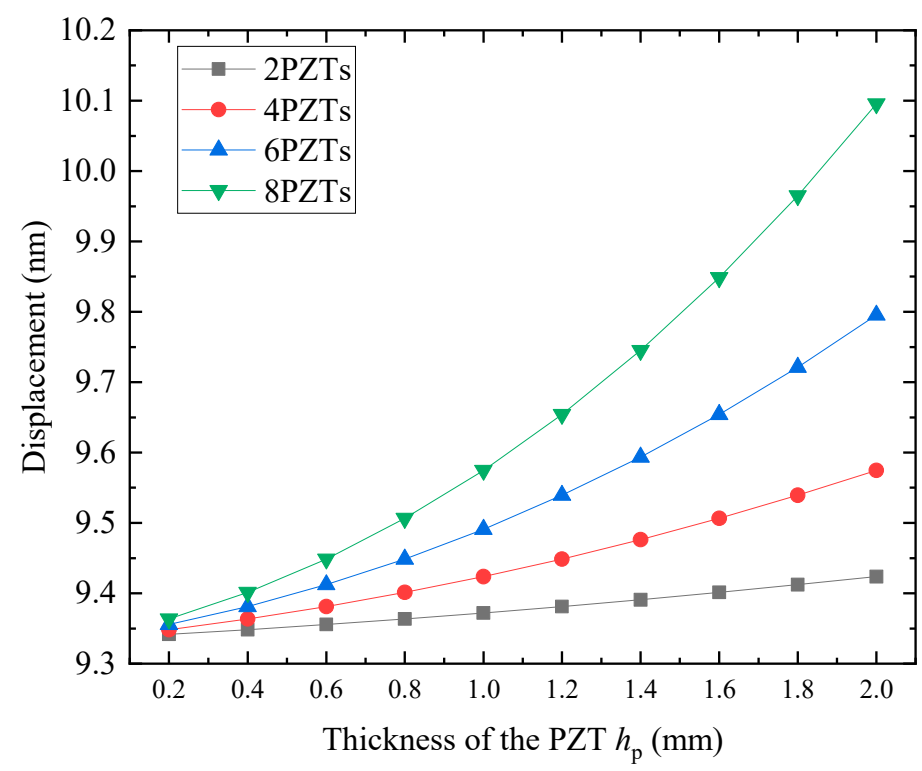

Figure 8. The influence of the thickness of the PZT disc $h_{\mathrm{p}}$ on the displacement at $z=h_{l 1}$.

\subsection{Influence of the Outer Diameter of Protective Shield}

Figure 9 shows the influence of the outer diameter $d_{0}$ of the protective shell on the first resonance frequency and the first electromechanical factor, and Figure 10 illustrates the relationship between the displacement at $z=h_{l 1}$ and the outer diameter $d_{o}$ of the protective shell at the frequency $f=20 \mathrm{kHz}$. Figure 9 demonstrates that the first resonance frequency increases $23.4-23.86 \%$ as the outer diameter of the protective shell increases from $12.4 \mathrm{~mm}$ to $16 \mathrm{~mm}$, while the first electromechanical coupling factor decreases $32.66-33.5 \%$. Figure 10 indicates that the displacement decreases $64.41-64.76 \%$ as the outer diameter of the protective shell increases from $12.4 \mathrm{~mm}$ to $16 \mathrm{~mm}$.

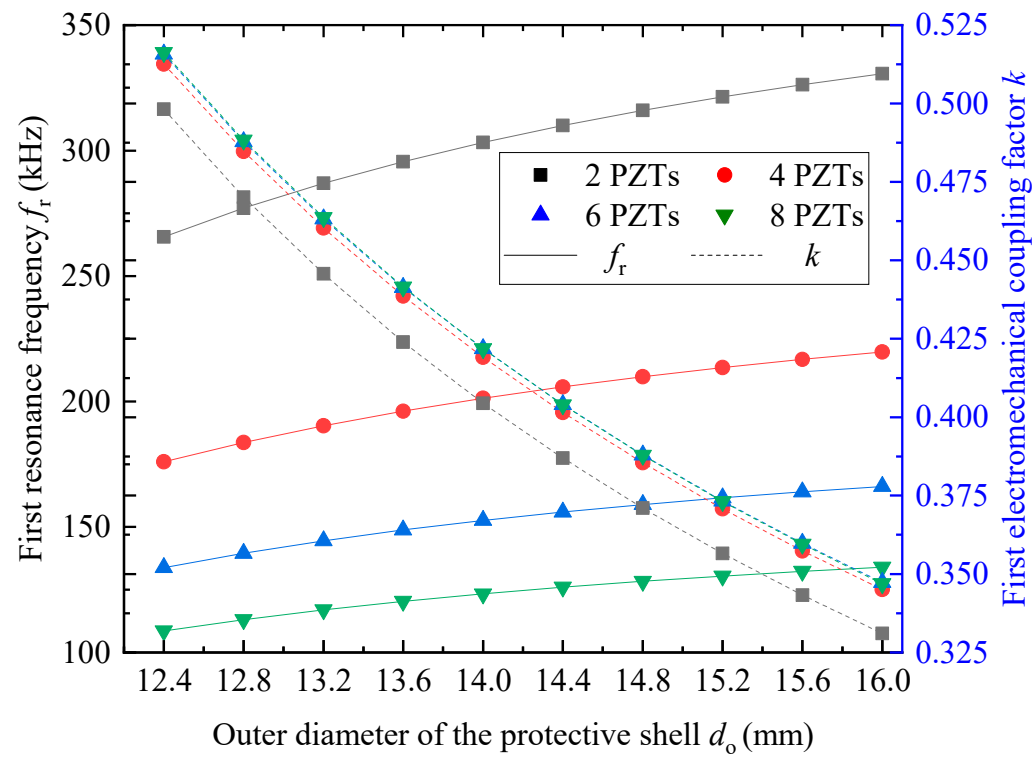

Figure 9. The influence of the outer diameter of the protective shell $d_{\mathrm{o}}$ on the first resonance frequency and electromechanical factor. 


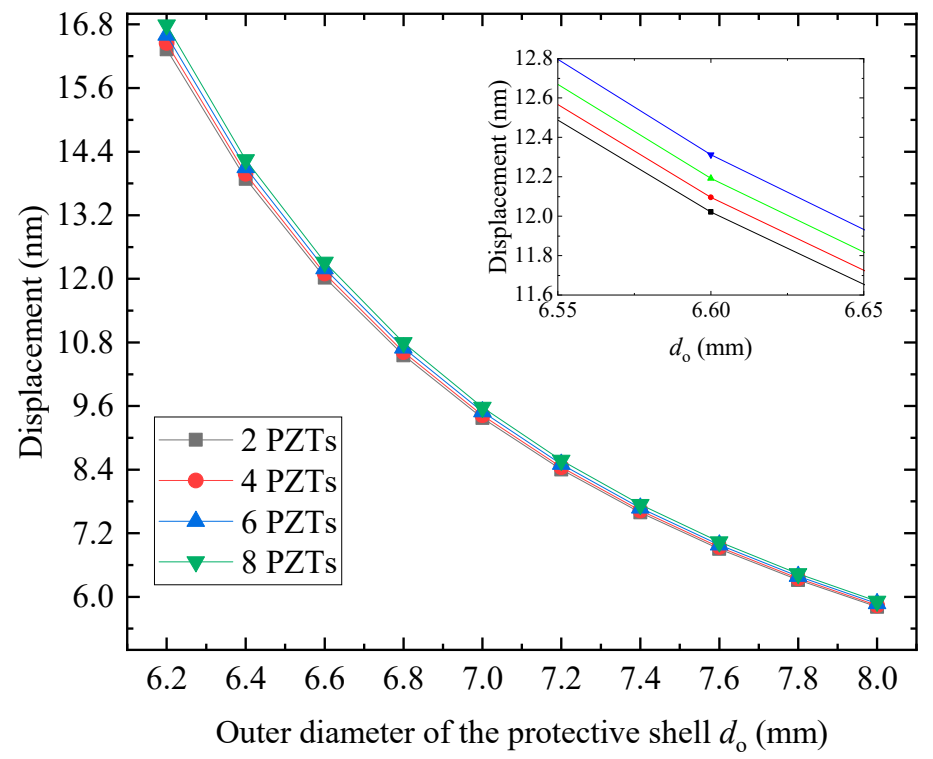

Figure 10. The influence of the outer diameter $d_{\mathrm{o}}$ of the protective shell on the displacement at $z=h_{l 1}$ with the frequency $f=20 \mathrm{kHz}$.

\subsection{Influence of the Thickness of Copper Lid}

Figure 11 shows the influence of the thickness $h_{l}$ of the two copper lids on the first resonance frequency and the first electromechanical factor, and Figure 12 illustrates the relationship between the displacement at $z=h_{l 1}$ and the thickness $h_{l}$ of the copper lid at the frequency $f=20 \mathrm{kHz}$. Figure 11 indicates that the first resonance frequency decreases $44.21-68.31 \%$ as the thickness of the copper lid increases from $0.2 \mathrm{~mm}$ to $3 \mathrm{~mm}$, and the coupling factor firstly increases to the peak value and then decreases, and the change of the coupling factor is $0.7-17.8 \%$. Figure 12 reveals that the displacement at $z=h_{l 1}$ with the frequency $f=20 \mathrm{kHz}$ increases $1.59-4.41 \%$ as the thickness of the copper lid increases.

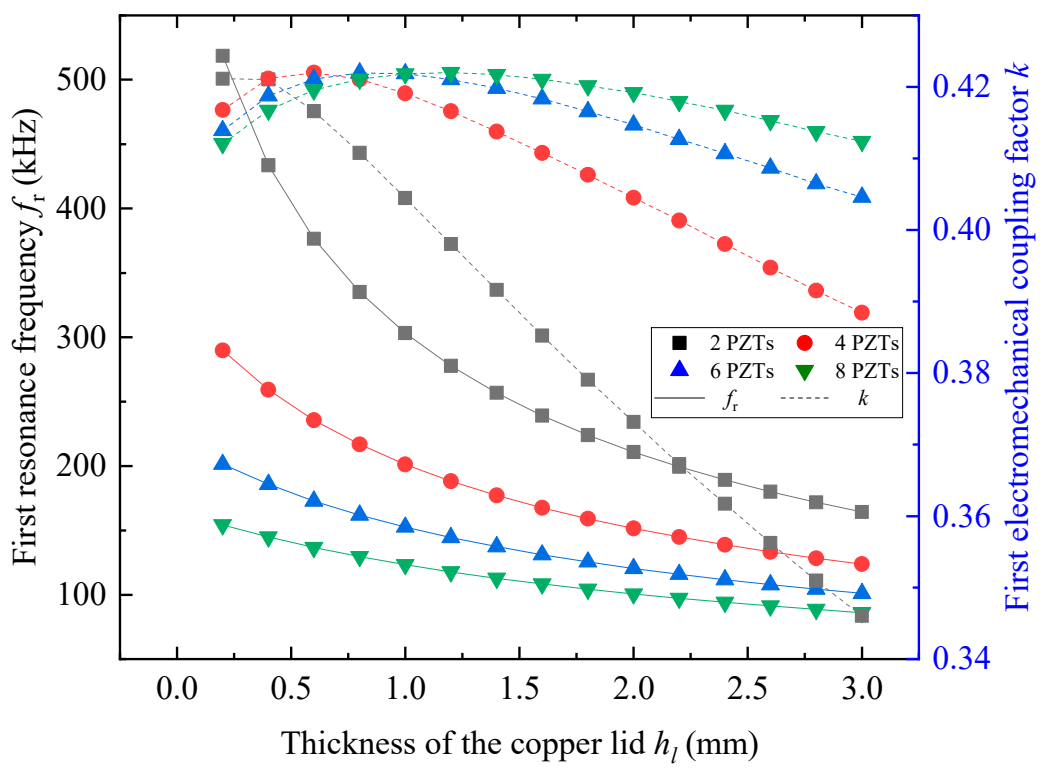

Figure 11. The influence of the thickness $h_{l}$ of the copper lid on the first resonance frequency and electromechanical factor. 


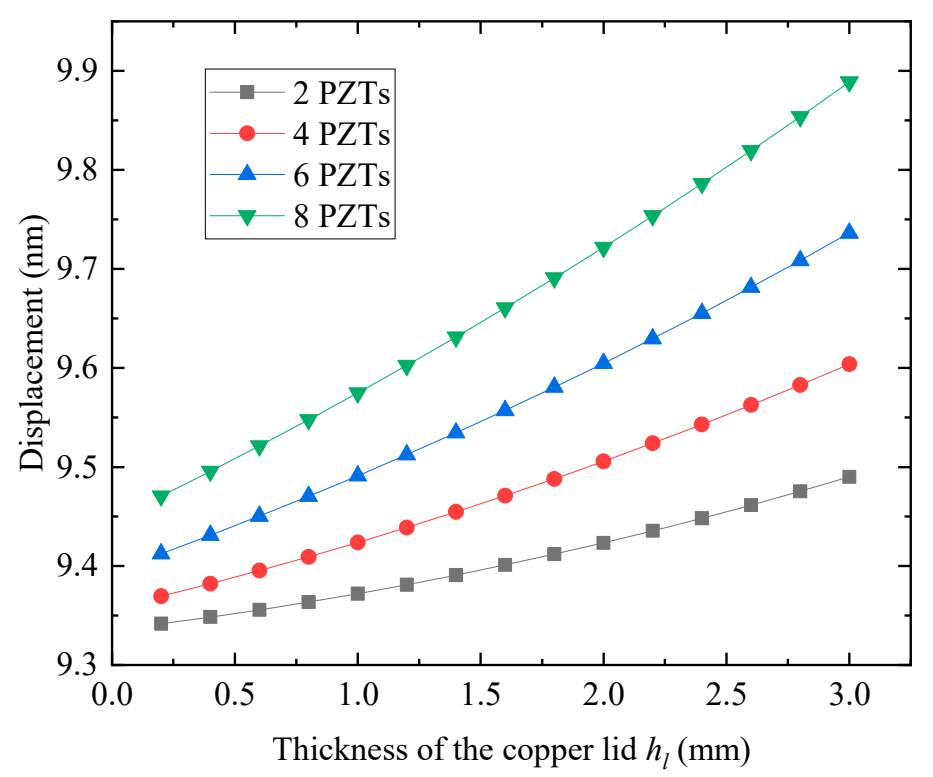

Figure 12. The influence of the thickness $h_{l}$ of the copper lid on the displacement at $z=h_{l 1}$ with the frequency $f=20 \mathrm{kHz}$.

\subsection{Influence of Epoxy}

Figure 13 shows the influence of the elastic modulus $C_{33 e}$ of the epoxy between the clearance between the protective shell and the PZT discs on the first resonance frequency and electromechanical coupling factor, and Figure 14 plots the displacement at $z=h_{l 1}$ versus the elastic modulus $C_{33 e}$ of epoxy with the frequency $f=20 \mathrm{kHz}$. Figure 13 indicates that the first resonance frequency just changes $0.79-0.90 \%$ as the elastic modulus increases from 1.28 GPa to $5.12 \mathrm{GPa}$. Figure 14 also shows that the first electromechanical coupling factor just decreases $0.46-0.52 \%$ as the elastic modulus $C_{33 e}$ changes from $1.28 \mathrm{GPa}$ to $5.12 \mathrm{GPa}$. Figure 14 reveals that the displacement at $z=h_{l 1}$ decreases $1.75-1.79 \%$ when the modulus $C_{33 e}$ changes from $1.28 \mathrm{GPa}$ to $5.12 \mathrm{GPa}$.

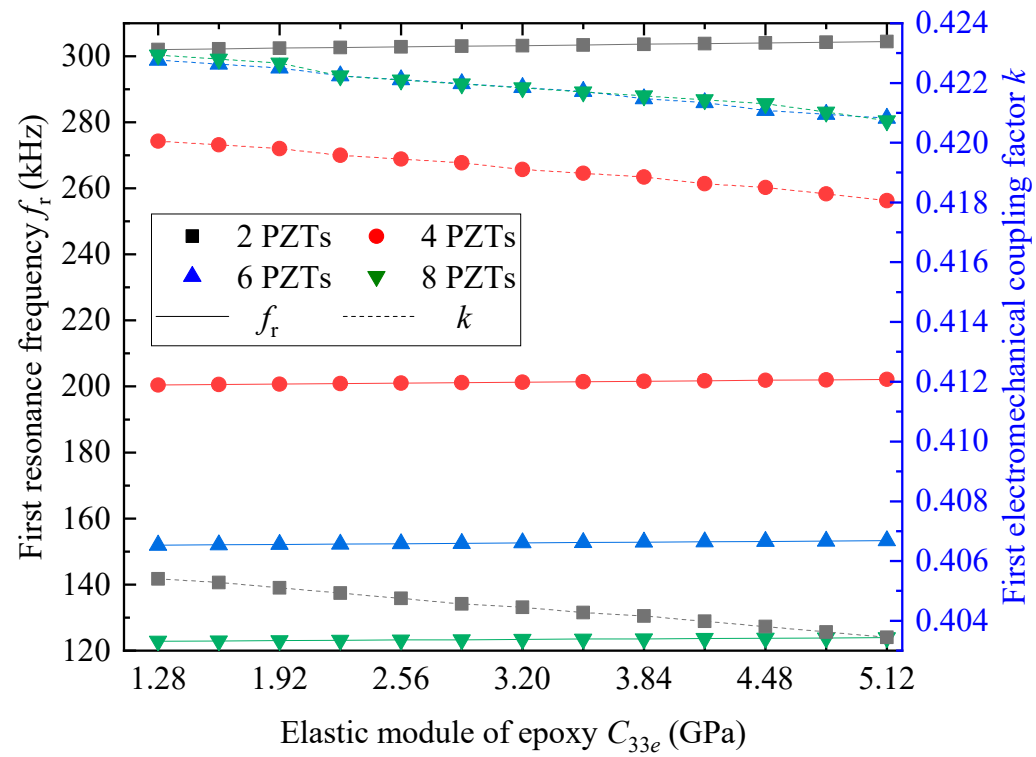

Figure 13. The influence of the elastic modulus $C_{33 e}$ of epoxy on the first resonance frequency and electromechanical factor. 


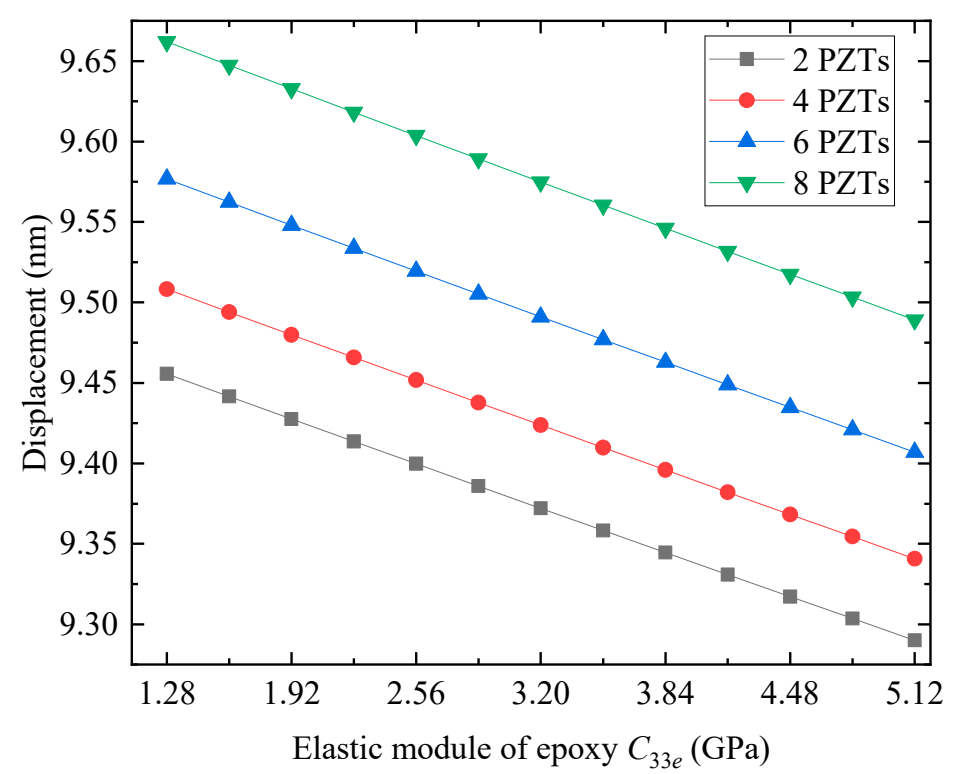

Figure 14. The influence of the elastic modulus $C_{33 e}$ of epoxy on the displacement at $z=h_{11}$ with the frequency $f=20 \mathrm{kHz}$.

\subsection{Experimental Validation}

As shown in Figure 15, to verify the proposed one-dimensional axial model, two SAPSs with 4 PZT discs and 6 PZT discs were assembled. In the experimental setup, as shown in Figure 16, the impedance of the two SAPSs was measured and recorded by a Wayne Kerr 6500B high-precision impedance meter (Wayne Kerr Electronic Instrument Co., Shenzhen, China) and a laptop.

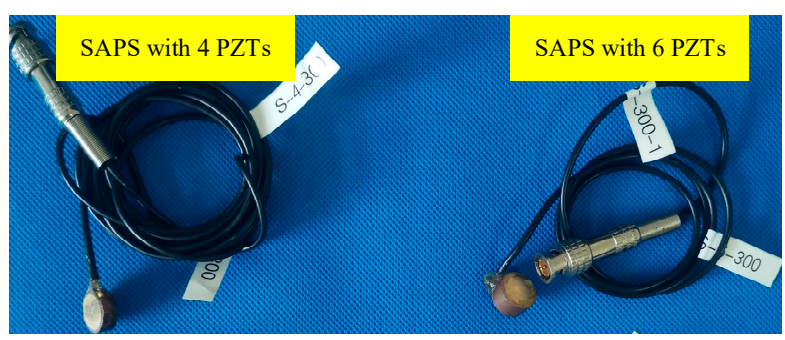

Figure 15. The fabricated SAPSs with different numbers of PZT discs.

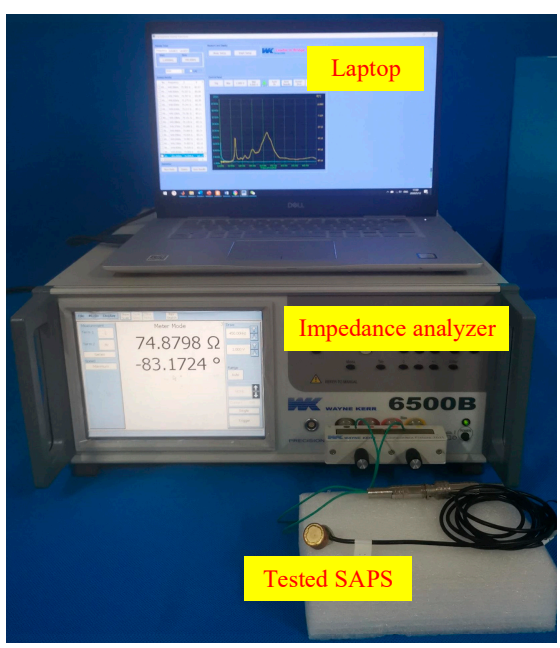

Figure 16. Experimental setup. 
The measured impedance signatures of the SAPSs with 4 PZT discs and 6 PZT discs are plotted in Figure 17, and the measured and experimental resonance and anti-resonance frequencies are listed in Table 3. The results in Table 3 indicate that the relative error between the theoretical and experimental frequencies is less than $3.15 \%$, which demonstrates that the resonance and anti-resonance frequencies obtained by the proposed model are consistent with the measured ones, and the proposed one-dimensional axial model can be employed to investigate SAPS's characteristics.

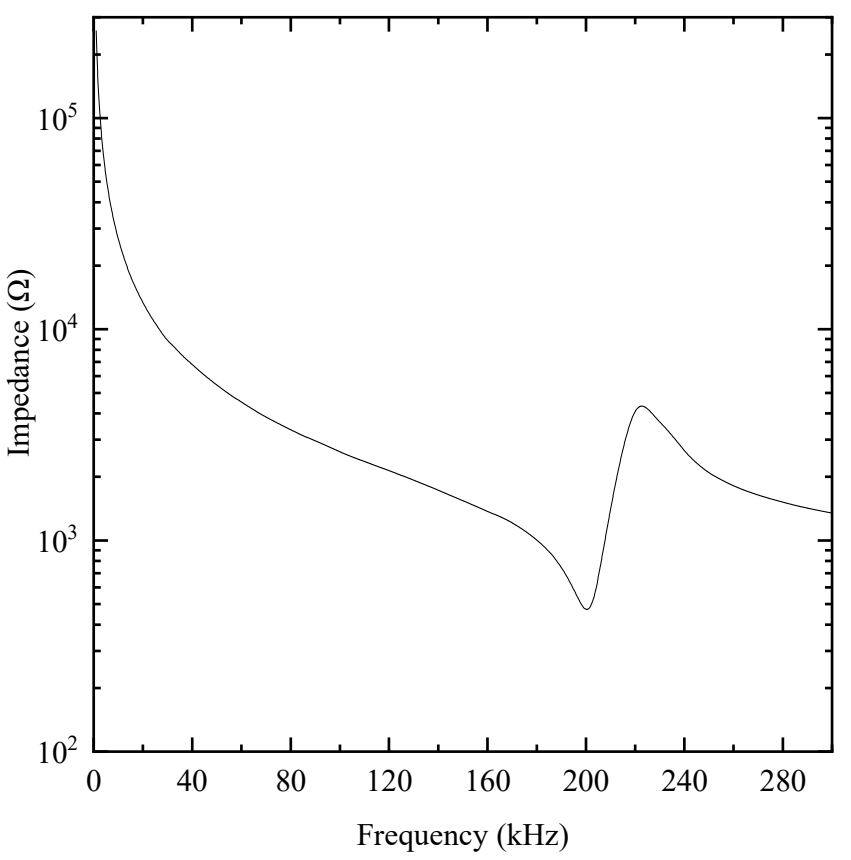

(a)

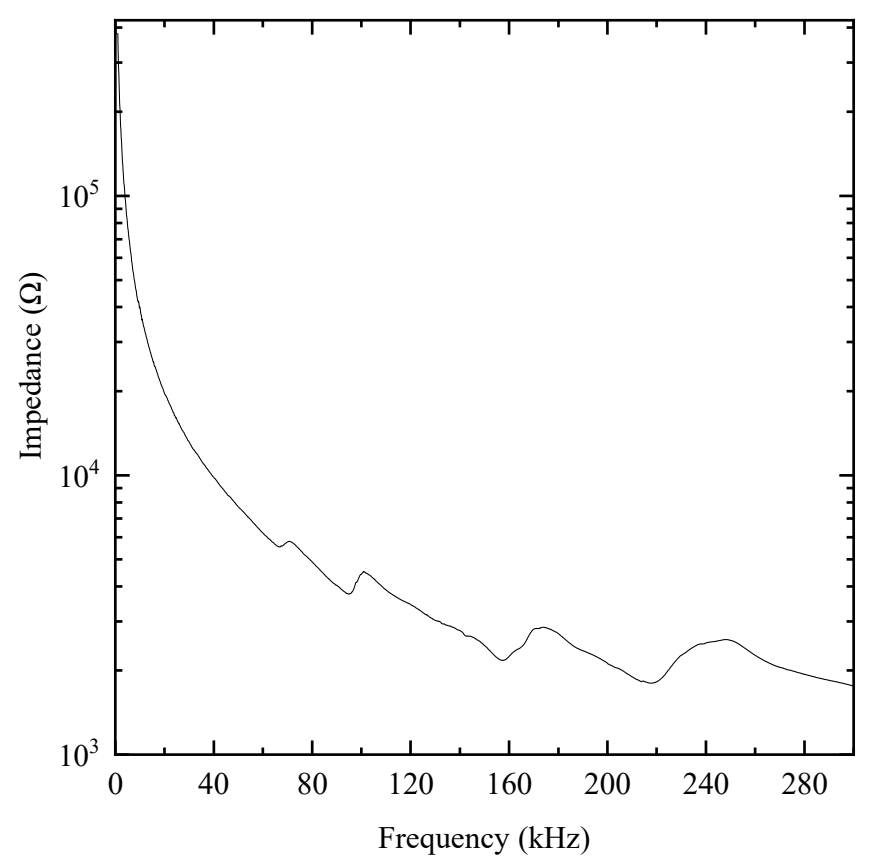

(b)

Figure 17. The impedance signatures of SAPSs with 4 and 6 PZT discs: (a) a SAPS with 4 PZT discs; (b) a SAPS with 6 PZT discs.

Table 3. Theoretical and experimental resonance and anti-resonance frequencies of the two SAPSs.

\begin{tabular}{lcccccc}
\hline & \multicolumn{3}{c}{ Resonance Frequency $\mathbf{( k H z )}$} & \multicolumn{3}{c}{ Anti-Resonance Frequency (kHz) } \\
& Measured & Theoretical & Relative Error & Measured & Theoretical & Relative Error \\
\hline 4 PZT discs & 202.8 & 201.29 & 0.74 & 222.6 & 221.7 & 0.40 \\
6 PZT discs & 156.3 & 152.61 & 2.36 & 173.8 & 168.32 & 3.15 \\
\hline
\end{tabular}

\subsection{Discussion}

In this section, the electromechanical and displacement output performance of SAPSs is discussed by using the proposed one-dimensional model, and an experimental setup was designed to verify the proposed model. The analyses indicate that the structural parameters, including the thickness and number of the PZT disc, the diameter of the protective shell, and thickness of the copper lids, have an influence on the SAPS's electromechanical performance, while only the thickness and number of the PZT discs and the thickness of the protective shell have an obvious effect on the displacement output of SAPSs. Moreover, the elastic modulus of the epoxy has a very limited influence on both the electromechanical and displacement output performance of SAPSsl and it will be helpful in the design of SAPSs.

\section{Conclusions}

A new type of smart aggregate using piezoceramic stack (SAPS) was developed in this research for improved output, as compared with a conventional smart aggregate with 
a single piezoceramic patch. The proposed smart aggregate is preferred for applications with a strong stress wave attenuating effect. To investigate its characteristics, the proposed SAPS was simplified to a one-dimensional axial model. Based on the simplified model, the influences of the structural parameters, including the number of the PZT discs, the dimension of the PZT disc, protective shield, and copper lids, and the elastic modulus of the epoxy on the electromechanical and displacement output performance were discussed by using numerical method. The results indicate that the number and thickness of the PZT discs have a greater effect on the first resonance frequency and the first electromechanical coupling factor of SAPSs than the dimensions of the protective shell and copper lids. Moreover, the results also show that the number of the PZT discs and the outer diameter of the protective shell have a much greater influence on the displacement output than other parameters. The results also demonstrate that the first resonance frequency, the first electromechanical coupling factor, and the displacement output of SAPSs change less than $1.79 \%$ when the elastic modulus of the epoxy changes from 1.28 GPa to $5.12 \mathrm{GPa}$, which demonstrates that the elastic modulus of the epoxy has a very limited influence on the property of SAPSs, and it will be helpful in the design and fabrication of SAPSs. Lastly, an experimental setup was designed, and experimental results validate the proposed model.

This study provides an approach to increasing the output of SAs and also presents a method to design SAPSs. Future research will involve SAPS's sensing performance study, and it will also involve damage detection by using SAPSs.

Author Contributions: Conceptualization, methodology, formal analysis, G.L.; validation, Q.W. and Z.L.; writing - original draft preparation, G.L. and H.S.; writing-review and editing, T.W.; supervision, G.L.; funding acquisition, G.L. All authors have read and agreed to the published version of the manuscript.

Funding: This research was funded by the National Natural Science Foundation of China, Grant Number 51808417.

Institutional Review Board Statement: Not applicable.

Informed Consent Statement: Not applicable.

Data Availability Statement: Not applicable.

Conflicts of Interest: The authors declare that they have no conflict of interest.

\section{References}

1. Mishra, M.; Barman, S.K.; Maity, D.; Maiti, D.K. Ant lion optimisation algorithm for structural damage detection using vibration data. J. Civ. Struct. 2019, 9, 117-136. [CrossRef]

2. Kim, I.-H.; Jeon, H.; Baek, S.-C.; Hong, W.H.; Jung, H.-J. Application of Crack Identification Techniques for an Aging Concrete Bridge Inspection Using an Unmanned Aerial Vehicle. Sensors 2018, 18, 1881. [CrossRef] [PubMed]

3. Peng, J.; Xiao, L.; Zhang, J.; Cai, C.S.; Wang, L. Flexural behavior of corroded HPS beams. Eng. Struct. 2019, 195, $274-287$. [CrossRef]

4. Huo, L.; Li, C.; Jiang, T.; Li, H.-N. Feasibility Study of Steel Bar Corrosion Monitoring Using a Piezoceramic Transducer Enabled Time Reversal Method. Appl. Sci. 2018, 8, 2304. [CrossRef]

5. Peng, J.; Hu, S.; Zhang, J.; Cai, C.S.; Li, L.-y. Influence of cracks on chloride diffusivity in concrete: A five-phase mesoscale model approach. Constr. Build. Mater. 2019, 197, 587-596. [CrossRef]

6. Giagopoulos, D.; Arailopoulos, A.; Dertimanis, V.; Papadimitriou, C.; Chatzi, E.; Grompanopoulos, K. Structural health monitoring and fatigue damage estimation using vibration measurements and finite element model updating. Struct. Health Monit. 2018, 18, 1189-1206. [CrossRef]

7. Li, N.; Wang, F.; Song, G. New Entropy-based Vibro-acoustic Modulation Method for Metal Fatigue Crack Detection: An Exploratory Study. Measurement 2019, 150, 107075. [CrossRef]

8. Giordano, P.F.; Prendergast, L.J.; Limongelli, M.P. A framework for assessing the value of information for health monitoring of scoured bridges. J. Civ. Struct. 2020, 10, 485-496. [CrossRef]

9. Furinghetti, M.; Pavese, A.; Lunghi, F.; Silvestri, D. Strategies of structural health monitoring for bridges based on cloud computing. J. Civ. Struct. 2019, 9, 607-616. [CrossRef]

10. Song, G.; Wang, C.; Wang, B. Structural Health Monitoring (SHM) of Civil Structures. Appl. Sci. 2017, 7, 789. [CrossRef]

11. Lei, B.; Ren, Y.; Wang, N.; Huo, L.; Song, G. Design of a new low-cost unmanned aerial vehicle and vision-based concrete crack inspection method. Struct. Health Monit. 2020, 19, 1871-1883. [CrossRef] 
12. Jing, X.; Wang, C.; Li, H.; Zhang, C.; Hao, J.; Fan, S. Health Monitoring of Bolted Spherical Joint Connection Based on Active Sensing Technique Using Piezoceramic Transducers. Sensors 2018, 18, 1727. [CrossRef]

13. Kong, Q.; Fan, S.; Bai, X.; Mo, Y.; Song, G. A Novel Embeddable Spherical Smart Aggregate for Structural Health Monitoring Part I. Fabrication and Electrical Characterization. Smart Mater. Struct. 2017, 26, 095050. [CrossRef]

14. Lu, G.; Li, Y.; Song, G. A delay-and-Boolean-ADD imaging algorithm for damage detection with a small number of piezoceramic transducers. Smart Mater. Struct. 2016, 25, 095030. [CrossRef]

15. Cheng, H.; Wang, F.; Huo, L.; Song, G. Detection of sand deposition in pipeline using percussion, voice recognition, and support vector machine. Struct. Health Monit. 2020, 19, 2075-2090. [CrossRef]

16. Wang, F.; Song, G. Monitoring of multi-bolt connection looseness using a novel vibro-acoustic method. Nonlinear Dyn. 2020, 136, 106507. [CrossRef]

17. He, S.; Wang, N.; Ho, M.; Zhu, J.; Song, G. Design of a New Stress Wave Communication Method for Underwater Communication. IEEE Trans. Ind. Electron. 2020, 68, 7370-7379. [CrossRef]

18. Lu, G.; Li, Y.; Wang, T.; Xiao, H.; Huo, L.; Song, G. A multi-delay-and-sum imaging algorithm for damage detection using piezoceramic transducers. J. Intel. Mat. Syst. Str. 2017, 28, 1150-1159. [CrossRef]

19. Wang, F.; Song, G. Bolt early looseness monitoring using modified vibro-acoustic modulation by time-reversal. Mech. Syst. Signal Process. 2019, 130, 349-360. [CrossRef]

20. Ma, Y.; Ji, Q.; Chen, S.; Song, G. An experimental study of ultra-low power wireless sensor-based autonomous energy harvesting system. J. Renew. Sustain. Energy 2017, 9, 054702. [CrossRef]

21. Ji, Q.; Ding, Z.; Wang, N.; Pan, M.; Song, G. A Novel Waveform Optimization Scheme for Piezoelectric Sensors Wire-Free Charging in the Tightly Insulated Environment. IEEE Internet Things 2018, 5, 1936-1946. [CrossRef]

22. Lu, G.; Li, Y.; Zhou, M.; Feng, Q.; Song, G. Detecting Damage Size and Shape in a Plate Structure Using PZT Transducer Array. J. Aerosp. Eng. 2018, 31, 04018075. [CrossRef]

23. Xu, C.; Du, S.; Gong, P.; Li, Z.; Chen, G.; Song, G. An Improved Method for Pipeline Leakage Localization with a Single Sensor Based on Modal Acoustic Emission and Empirical Mode Decomposition with Hilbert Transform. IEEE Sens. J. 2020, 20, 5480-5491. [CrossRef]

24. Liu, Y.; Zhang, M.; Yin, X.; Huang, Z.; Wang, L. Debonding Detection of Reinforced Concrete (RC) Beam with Near-Surface Mounted (NSM) Pre-stressed Carbon Fiber Reinforced Polymer (CFRP) Plates Using Embedded Piezoceramic Smart Aggregates (SAs). Appl. Sci. 2020, 10, 50. [CrossRef]

25. Zhou, L.; Zheng, Y.; Song, G.; Chen, D.; Ye, Y. Identification of the structural damage mechanism of BFRP bars reinforced concrete beams using smart transducers based on time reversal method. Constr. Build. Mater. 2019, 220, 615-627. [CrossRef]

26. Chen, D.; Huo, L.; Song, G. EMI based multi-bolt looseness detection using series/parallel multi-sensing technique. Smart Struct. Syst. 2020, 25, 423-432. [CrossRef]

27. Guo, B.; Chen, D.; Huo, L.; Song, G. Monitoring of Grouting Compactness in Tendon Duct Using Multi-Sensing Electro-Mechanical Impedance Method. Appl. Sci. 2020, 10, 2018. [CrossRef]

28. Zuo, C.; Feng, X.; Zhou, J. A Three-Dimensional Model of the Effective Electromechanical Impedance for an Embedded PZT Transducer. Math. Probl. Eng. 2013, 2013, 218026. [CrossRef]

29. Song, G.; Gu, H.; Mo, Y.L.; Hsu, T.T.C.; Dhonde, H. Concrete structural health monitoring using embedded piezoceramic transducers. Smart Mater. Struct. 2007, 16, 959-968. [CrossRef]

30. Song, G.; Gu, H.; Mo, Y.-L. Smart aggregates: Multi-functional sensors for concrete structures-a tutorial and a review. Smart Mater. Struct. 2008, 17, 033001. [CrossRef]

31. Song, G.; Mo, Y.L.; Otero, K.; Gu, H. Health monitoring and rehabilitation of a concrete structure using intelligent materials. Smart Mater. Struct. 2006, 15, 309. [CrossRef]

32. Kong, Q.; Wang, R.; Song, G.; Yang, Z.J.; Still, B. Monitoring the soil freeze-thaw process using piezoceramic-based smart aggregate. J. Cold Reg. Eng. 2014, 28, 06014001. [CrossRef]

33. Li, W.; Kong, Q.; Ho, S.C.M.; Mo, Y.; Song, G. Feasibility study of using smart aggregates as embedded acoustic emission sensors for health monitoring of concrete structures. Smart Mater. Struct. 2016, 25, 115031. [CrossRef]

34. Zou, D.; Liu, T.; Yang, A.; Zhao, Y.; Du, C. A primary study on the performance of piezoceramic based smart aggregate under various compressive stresses. Smart Mater. Struct. 2017, 26, 107003. [CrossRef]

35. Siu, S.; Ji, Q.; Wu, W.; Song, G.; Ding, Z. Stress wave communication in concrete: I. Characterization of a smart aggregate based concrete channel. Smart Mater. Struct. 2014, 23, 125030. [CrossRef]

36. Hou, S.; Zhang, H.; Ou, J. A PZT-based smart aggregate for compressive seismic stress monitoring. Smart Mater. Struct. 2012, 21, 105035. [CrossRef]

37. Voutetaki, M.E.; Papadopoulos, N.A.; Angeli, G.M.; Providakis, C.P. Investigation of a new experimental method for damage assessment of RC beams failing in shear using piezoelectric transducers. Eng. Struct. 2016, 114, 226-240. [CrossRef]

38. Kong, Q.; Robert, R.; Silva, P.; Mo, Y.L. Cyclic Crack Monitoring of a Reinforced Concrete Column under Simulated PseudoDynamic Loading Using Piezoceramic-Based Smart Aggregates. Appl. Sci. 2016, 6, 341. [CrossRef]

39. Xu, K.; Deng, Q.; Cai, L.; Ho, S.; Song, G. Damage Detection of a Concrete Column Subject to Blast Loads Using Embedded Piezoceramic Transducers. Sensors 2018, 18, 1377. [CrossRef] 
40. Zhu, J.; Ho, S.C.M.; Kong, Q.; Patil, D.; Mo, Y.-L.; Song, G. Estimation of impact location on concrete column. Smart Mater. Struct. 2017, 26, 055037. [CrossRef]

41. Song, G.; Olmi, C.; Gu, H. An overheight vehicle-bridge collision monitoring system using piezoelectric transducers. Smart Mater. Struct. 2007, 16, 462. [CrossRef]

42. Feng, Q.; Kong, Q.; Huo, L.; Song, G. Crack detection and leakage monitoring on reinforced concrete pipe. Smart Mater. Struct. 2015, 24, 115020. [CrossRef]

43. Zeng, L.; Parvasi, S.M.; Kong, Q.; Huo, L.; Li, M.; Song, G. Bond slip detection of concrete-encased composite structure using shear wave based active sensing approach. Smart Mater. Struct. 2015, 24, 125026. [CrossRef]

44. Jiang, T.; Kong, Q.; Patil, D.; Luo, Z.; Huo, L.; Song, G. Detection of debonding between fiber reinforced polymer bar and concrete structure using piezoceramic transducers and wavelet packet analysis. IEEE Sens. J. 2017, 17, 1992-1998. [CrossRef]

45. Du, P.; Xu, D.; Huang, S.; Cheng, X. Assessment of corrosion of reinforcing steel bars in concrete using embedded piezoelectric transducers based on ultrasonic wave. Constr. Build. Mater. 2017, 151, 925-930. [CrossRef]

46. Zou, D.; Liu, T.; Qiao, G.; Huang, Y.; Li, B. An experimental study on the performance of piezoceramic-based smart aggregate in water environment. IEEE Sens. J. 2014, 14, 943-944. [CrossRef]

47. Kong, Q.; Feng, Q.; Song, G. Water presence detection in a concrete crack using smart aggregates. Int. J. Smart Nano Mater. 2015, 6, 149-161. [CrossRef]

48. Talakokula, V.; Bhalla, S.; Gupta, A. Monitoring early hydration of reinforced concrete structures using structural parameters identified by piezo sensors via electromechanical impedance technique. Mech. Syst. Signal Process. 2018, 99, 129-141. [CrossRef]

49. Taghavipour, S.; Kharkovsky, S.; Kang, W.-H.; Samali, B.; Mirza, O. Detection and monitoring of flexural cracks in reinforced concrete beams using mounted smart aggregate transducers. Smart Mater. Struct. 2017, 26, 104009. [CrossRef]

50. Noori Hoshyar, A.; Samali, B.; Liyanapathirana, R.; Taghavipour, S. Analysis of failure in concrete and reinforced-concrete beams for the smart aggregate-based monitoring system. Struct. Health Monit. 2020, 19, 463-480. [CrossRef]

51. Gu, H.; Moslehy, Y.; Sanders, D.; Song, G.; Mo, Y. Multi-functional smart aggregate-based structural health monitoring of circular reinforced concrete columns subjected to seismic excitations. Smart Mater. Struct. 2010, 19, 065026. [CrossRef]

52. Wang, J.; Kong, Q.; Shi, Z.; Song, G. Electromechanical properties of smart aggregate: Theoretical modeling and experimental validation. Smart Mater. Struct. 2016, 25, 095008. [CrossRef]

53. Huo, L.; Li, X.; Li, H.; Wang, Z.; Song, G. Dynamic modelling of embeddable piezoceramic transducers. Sensors 2017, $17,2801$. [CrossRef] [PubMed]

54. Gao, W.; Li, H.; Ho, S.C.M. A Novel Embeddable Tubular Piezoceramics-Based Smart Aggregate for Damage Detection in Two-Dimensional Concrete Structures. Sensors 2019, 19, 1501. [CrossRef] [PubMed]

55. Gao, W.; Huo, L.; Li, H.; Song, G. Smart concrete slabs with embedded tubular PZT transducers for damage detection. Smart Mater. Struct. 2018, 27, 025002. [CrossRef]

56. Gao, W.; Huo, L.; Li, H.; Song, G. An embedded tubular PZT transducer based damage imaging method for two-dimensional concrete structures. IEEE Access 2018, 6, 30100-30109. [CrossRef]

57. Kong, Q.; Fan, S.; Mo, Y.; Song, G. A novel embeddable spherical smart aggregate for structural health monitoring: Part II. Numerical and experimental verifications. Smart Mater. Struct. 2017, 26, 095051. [CrossRef]

58. Yan, S.; Ma, H.; Li, P.; Song, G.; Wu, J. Development and application of a structural health monitoring system based on wireless smart aggregates. Sensors 2017, 17, 1641. [CrossRef]

59. Lin, S.; Fu, Z.; Zhang, X.; Wang, Y.; Hu, J. Radially sandwiched cylindrical piezoelectric transducer. Smart Mater. Struct. 2012, 22, 015005. [CrossRef]

60. Wang, J.; Shi, Z.; Han, Z. Analytical solution of piezoelectric composite stack transducers. J. Intel. Mat. Syst. Str. 2013, 24, 1626-1636. [CrossRef]

61. Wang, J.; Shi, Z. Electromechanical analysis of 2-2 cement-based piezoelectric transducers in series electrically. Smart Struct. Syst. 2014, 14, 267-284. [CrossRef]

62. Lin, S. The radial composite piezoelectric ceramic transducer. Sensor. Actuat. A Phys. 2008, 141, 136-143. [CrossRef]

63. Lu, G.; Feng, Q.; Li, Y.; Wang, H.; Song, G. Characterization of Ultrasound Energy Diffusion Due to Small-Size Damage on an Aluminum Plate Using Piezoceramic Transducers. Sensors 2017, 17, 2796. [CrossRef] [PubMed]

64. Mason, W.; Baerwald, H. Piezoelectric Crystals and Their Applications to Ultrasonics. Phys. Today 1951, 4, 23. [CrossRef] 